\title{
SISTEM MONITORING KUALITAS UDARA SECARA REALTIME DENGAN PERINGATAN BAHAYA KUALITAS UDARA TIDAK SEHAT MENGGUNAKAN PUSH NOTIFICATION
}

\author{
Ikhwan Prayoga ${ }^{1}$, Dedi Triyanto ${ }^{2}$, Suhardi $^{3}$ \\ ${ }^{123}$ Jurusan Rekayasa Sistem Komputer, Fakultas MIPA Universitas Tanjungpura \\ Jalan Prof. Dr. H. Hadari Nawawi Pontianak \\ Telp./Fax : (0561) 577963 \\ e-mail: 1yoga.seke@gmail.com, ²dedi.triyanto@ siskom.untan.ac.id, \\ ${ }^{3}$ suhardi@siskom.untan.ac.id.
}

\begin{abstract}
Abstrak
Udara merupakan suatu campuran gas yang terdapat pada lapisan yang mengelilingi bumi. Kualitas udara penting untuk kehidupan makhluk hidup terutama bagi manusia. Pada penelitian ini dibuat suatu sistem monitoring kualitas udara secara realtime. Selain melakukan monitoring sistem ini juga akan mengirimkan push notification kepada pengguna ketika kualitas udara berada pada kategori tidak sehat, sangat tidak sehat atau berbahaya. Sistem yang dibuat akan melakukan pengukuran PM10, pengukuran karbon monoksida, deteksi asap, pengukuran suhu dan kelembapan udara. Pengukuran konsentrasi PM10 menggunakan sensor GP2Y1010AU0F, pengukuran karbon monoksida menggunakan sensor MQ-7, deteksi asap menggunakan sensor MQ-2 serta pengukuran suhu dan kelembapan menggunakan sensor DHT-11. Proses pengiriman data ke server menggunakan NodeMCU yang telah terhubung ke jaringan wifi dan internet. Sistem yang dibuat telah berhasil melakukan monitoring kualitas udara secara realtime dan pengiriman push notification kepada pengguna. Penentuan kualitas udara di tentukan oleh nilai pengukuran PM10 dan karbon monoksida. Kualitas udara tidak sehat berada pada rentang pengukuran 101 sampai 199. Kualitas udara kategori sangat tidak sehat berada pada pengukuran 200 sampai 299. Kualitas udara kategori berbahaya berada pada pengukuran lebih dari 300 . Untuk satuan pengukuran PM10 yaitu $\mu \mathrm{g} / \mathrm{m}^{3}$ dan satuan pengukuran karbon monoksida yaitu ppm.
\end{abstract}

Keywords: Monitoring, Push Notification, Kualitas Udara, PM10, Karbon Monoksida, Asap, Suhu dan Kelembapan.

\section{PENDAHULUAN}

Udara merupakan suatu campuran gas yang terdapat pada lapisan yang mengelilingi bumi. Komposisi campuran gas tersebut tidak selalu konstan, komponen yang konsentrasinya paling bervariasi adalah air dalam bentuk uap $\left(\mathrm{H}_{2} \mathrm{O}\right)$ dan karbon dioksida $\left(\mathrm{CO}_{2}\right)$. Kualitas udara penting bagi kehidupan makhluk hidup di bumi, terutama untuk manusia sebagai proses pernapasan. Untuk sekarang kualitas udara di beberapa wilayah perkotaan semakin menurun. Menurunnya kualitas udara disebabkan oleh beberapa hal di antaranya pertumbuhan industri dan peningkatan jumlah kendaraan motor. Penurunan kualitas udara juga diakibatkan oleh kebakaran hutan, untuk di Kalimantan Barat kebakaran hutan selalu terjadi di setiap tahunnya. Menurut BMKG (Badan
Meteorologi Klimatologi dan Geofisika) Supadio Pontianak Pada tanggal 19 September 2019 tercatat ada 1.431 titik panas yang tersebar di seluruh Kabupaten/Kota di Kalimantan Barat. Dengan banyaknya titik api yang tersebar di Kalimantan Barat, tidak menutup kemungkinan akan menyebabkan kabut asap. Tidak hanya kabut asap, partikel kecil PM10 seperti debu sisa kebakaran akan tercampur dengan udara yang dapat menyebabkan polusi udara sehingga kualitas udara menurun yang akan berdampak negatif baik terhadap kesehatan manusia maupun lingkungan. Berdasarkan Indeks Standar Pencemaran Udara (ISPU) dari BMKG Pontianak pada Tanggal 19 September 2019 udara di Pontianak masuk dalam level berbahaya. Hal ini mengakibatkan penurunan jarak pandang berkisar 200 hingga 
300 meter. Masyarakat Kota Pontianak juga menggunakan masker ketika berkendara agar terhindar dari bahaya asap.

Merujuk dari permasalahan tersebut, maka selanjutnya akan dikembangkan sebuah sistem yang dapat melakukan pengukuran kualitas udara, yang terdiri dari pengukuran konsentrasi PM10, pengukuran konsentrasi $\mathrm{CO}$, deteksi asap dan pengukuran suhu serta kelembapan udara secara realtime. Parameter penentuan kualitas udara merujuk pada pengukuran PM10 dan CO. Sistem terdiri dari perangkat keras dan perangkat lunak, perangkat keras akan melakukan monitoring kualitas udara menggunakan beberapa sensor. Data yang diperoleh akan dikirim ke server dan akan diproses oleh perangkat lunak. Data yang sudah diproses akan diinformasikan kepada pengguna melalui website. Perangkat lunak akan melakukan pengiriman push notification kepada pengguna berupa informasi kategori kualitas udara dan rekomendasi yang dapat dilakukan untuk mengurangi dampak buruk ketika kualitas udara masuk pada kategori tidak sehat, sangat tidak sehat, atau berbahaya.

\section{LANDASAN TEORI}

\subsection{Kualitas Udara}

Udara merupakan suatu campuran gas yang terdapat pada lapisan yang mengelilingi bumi. Komposisi campuran gas tersebut tidak selalu konstan. Komponen yang konsentrasinya paling bervariasi adalah air dalam bentuk uap $\left(\mathrm{H}_{2} \mathrm{O}\right)$ dan karbon dioksida $\left(\mathrm{CO}_{2}\right)$. Udara di alam tidak terbebas dari polutan, contoh beberapa polutan yang terdapat di udara yaitu gas sulfur dioksida $\left(\mathrm{SO}_{2}\right)$, hidrogen sulfida $\left(\mathrm{H}_{2} \mathrm{~S}\right)$, dan karbon dioksida (CO) selalu dibebaskan ke udara sebagai produk sampingan dari proses-proses alami seperti aktivitas vulkanik, pembusukan sampah tanaman, kebakaran hutan dan sebagainya. Selain disebabkan polutan alami tersebut, polusi udara juga dapat disebabkan oleh aktivitas manusia seperti pembakaran lahan, sisa pembakaran mesin-mesin bermotor maupun dari limbah asap industri.

Penentuan standar kualitas udara yang digunakan di Indonesia adalah Indeks Standar Pencemar Udara (ISPU), hal ini sesuai dengan Keputusan Menteri Negara Lingkungan Hidup Nomor: KEP-45/MENLH/1997 Tentang Standar Pencemar Udara. Keputusan tersebut dipergunakan sebagai bahan pertimbangan di antaranya untuk memberikan kemudahan dari keseragaman informasi kualitas udara kepada masyarakat di lokasi dan waktu tertentu serta sebagai bahan pertimbangan dalam melakukan upaya-upaya pengendalian pencemaran udara. ISPU adalah angka yang tidak mempunyai satuan yang menggambarkan kondisi kualitas udara di lokasi dan waktu tertentu yang didasarkan kepada dampak terhadap kesehatan manusia, nilai estetika dan makhluk hidup lainnya. Indeks Standar Pencemar Udara ditetapkan dengan cara mengubah kadar pencemaran udara yang terukur menjadi suatu angka yang tidak berdimensi

Parameter pengukuran kualitas udara berdasarkan kualitas Indeks Standar Pencemar Udara dapat dilihat pada Tabel 1.

Tabel 1 Rentang Indeks Standar Pencemar Udara

\begin{tabular}{|c|c|}
\hline \multicolumn{2}{|c|}{ KEPMEN LH NOMOR : KEP- } \\
45/MENLH/10/1997 \\
\hline Kategori & Rentang \\
\hline Baik & $0-50$ \\
\hline Sedang & $51-100$ \\
\hline Tidak Sehat & $101-199$ \\
\hline Sangat Tidak Sehat & $200-299$ \\
\hline Berbahaya & $300-3000$ \\
\hline
\end{tabular}

\section{$2.2 \quad$ PM10}

PM10 merupakan salah satu bahan pencemar udara yang digolongkan ke dalam kelompok pencemar primer (primary polutant), yaitu bahan pencemar yang di emisikan langsung ke udara dari sumber cemaran, seperti kendaraan bermotor, sisa kebakaran hutan [1]. PM10 merupakan partikulat yang berukuran lebih kecil daripada 10 mikron. PM10 berasal dari debu jalan, debu konstruksi, pengangkutan material, buangan kendaraan, dan cerobong asap industri, serta aktivitas crushing dan grinding [2].

Di samping mengganggu estetika, partikel berukuran kecil di udara dapat terhisap ke dalam sistem pernapasan dan menyebabkan penyakit gangguan pernapasan serta kerusakan paru-paru. Pada level yang tidak sehat PM10 dapat menyebabkan kerusakan tanaman, pada level sangat tidak sehat PM10 dapat menyebabkan meningkatnya sensitivitas pada pasien berpenyakit asthma dan bronhitis, sedangkan pada level berbahaya PM10 dapat menyebabkan efek yang berbahaya kepada manusia, terutama pada sistem pernapasan. 


\subsection{Karbon Monoksida (CO)}

Karbon monoksida atau CO merupakan suatu gas yang mempunya sifat tidak berwarna, tidak berbau dan juga tidak berasa, pada suhu di bawah $129^{\circ} \mathrm{C}$ akan berbentuk air. Gas CO berasal dari pembakaran bahan fosil, yang menghasilkan sisa hasil pembakaran berupa gas buang. Sebagian besar gas CO dihasilkan dari sisa pembakaran mesin berbahan bakar bensin, selain itu gas $\mathrm{CO}$ dapat juga dihasilkan dari hasil proses kegiatan industri [3].

\subsection{Asap}

Asap merupakan dispersi uap asap dalam udara yang dihasilkan dari proses distilasi kering atau pirolisa biomassa seperti kayu, kulit kayu, tempurung, sabut, bambu, daun dan lain sebagainya. Asap diperoleh dari hasil pembakaran yang banyak mengandung selulosa, hemiselulosa dan lignin yang pembakarnya tidak sempurna, yaitu pembakaran dengan oksigen terbatas. Apabila pembakaran dilakukan dengan oksigen cukup hasilnya berupa uap air, gas asap arang dan abu, dalam kondisi ini tidak terbentuk asap. Sebaliknya jika pembakaran dilakukan dengan sedikit oksigen maka asap yang dihasilkan terdiri atas gas asap arang, alkohol dan asap organik lainya [4].

\subsection{Suhu dan Kelembapan}

Suhu menunjukkan derajat panas benda, semakin tinggi suhu suatu benda, maka semakin panas benda tersebut. Secara mikroskopis, suhu menunjukkan energi yang dimiliki oleh suatu benda. Setiap atom dalam suatu benda masing-masing bergerak baik itu dalam bentuk perpindahan maupun gerakan di tempat berupa getaran. Makin tinggi energi atom-atom penyusun benda, makin tinggi suhu benda tersebut. Suhu juga disebut temperatur, satuan suhu adalah Kelvin (K). Skala-skala lain adalah Celcius, Fahrenheit, dan Reamur [5].

Kelembapan udara adalah banyaknya uap air yang terkandung dalam udara atau atmosfer. Besarnya tergantung dari masuknya uap air ke dalam atmosfer karena adanya penguapan dari air yang ada di lautan, danau, sungai maupun dari air tanah. Disamping itu terjadi pula dari proses transpirasi, yaitu penguapan dari tumbuh-tumbuhan. Sedangkan banyaknya air di dalam udara bergantung kepada banyak faktor, antara lain adalah ketersediaan air, sumber uap, suhu udara, tekanan udara, dan angin.

\subsection{Arduino Nano}

Arduino nano adalah seri arduino yang memiliki bentuk yang relatif kecil jika dibandingkan dengan bentuk arduino pada umumnya. Arduino merupakan perangkat open source yang di peruntukan untuk mempermudah pengembangan perangkat keras dan perangkat lunak [6].

Bentuk fisik dari Arduino Nano dapat dilihat pada Gambar 1.

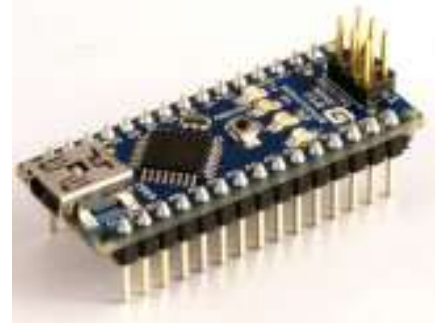

Gambar 1. Arduino Nano

\subsection{NodeMCU}

NodeMCU merupakan perangkat keras atau platform Internet Of Thing (IOT) yang open source seperti arduino. Paltform ini termasuk firmware yang berjalan pada ESP8266 Wi-Fi SoC dari Espressif System, dan pada perangkat keras yang berbasis modul ESP12 atau chip ESP8266-12E. NodeMCU pada dasarnya adalah pengembangan dari ESP8266 dengan firmware berbasis e-Lua [7].

NodeMCU memiliki fitur yang mendukung komunikasi TCP/IP. Board ini berbasis ESP8266 serial wifi SoC (Single on Chip), wireless yang digunakan adalah IEE $802.11 \mathrm{~b} / \mathrm{g} / \mathrm{n}$. Selian intu NodeMCU mendukung enkripsi WEP, WPA sehingga menjadikan chipset ini sangat aman digunakan. NodeMCU beroperasi pada tegangan 3,3V, mempunyai 11 pin GPIO sebagai input output, 1 pin Analog Digital Converter (ADC) [8]. Bentuk fisik dari NodeMCU dapat dilihat pada Gambar 2.

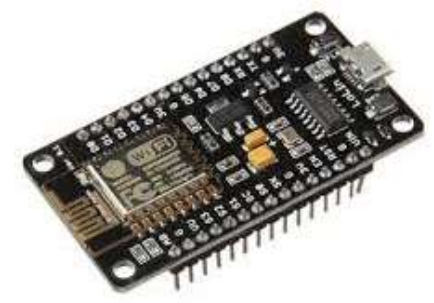

Gambar 2. NodeMCU 


\subsection{Sensor GP2Y1010AU0F}

Sensor GP2Y1010AU0F merupakan alat pengubah sinyal analog menjadi sinyal digital untuk mendeteksi kandungan partikulat debu, baik PM10 maupun PM2,5. Particulate Matter 10 (PM10) merupakan partikel yang memiliki diameter kurang dari $10 \mu \mathrm{m}$.

Spesifikasi dari sensor GP2Y1010AU0F sensitivitas $0,5 / 01 \mathrm{mg} / \mathrm{m}^{3}$ mengonsumsi daya sebesar $5 \mathrm{v}$, dapat beroperasi pada temperatur 10 sampai $66{ }^{\circ} \mathrm{C}$ [9]. Bentuk fisik dari sensor GP2Y1010AU0F dapat dilihat pada Gambar 3.

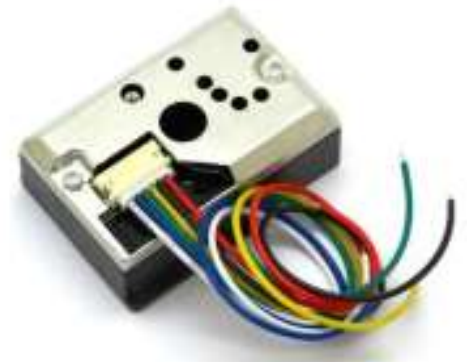

Gambar 3. Sensor GP2Y1010AU0F

\subsection{Sensor MQ-2}

Sensor MQ-7 merupakan sensor gas yang digunakan dalam peralatan untuk mendeteksi gas karbon monoksida (CO) dalam kehidupan sehari-hari. Sensor MQ-7 mempunyai sensitivitas yang tinggi terhadap karbon monoksida (CO), stabil, dan berumur panjang [10]. Spesifikasi dari sensor MQ-7 yaitu menggunakan tegangan input $5 \mathrm{~V}$, sensitivitas pengukuran gas karbon monoksida (CO) 20-2000 ppm [11]. Bentuk fisik dari sensor MQ-7 dapat dilihat pada Gambar 4.

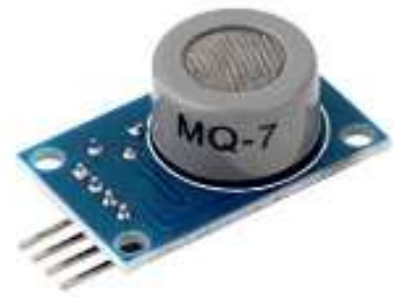

Gambar 4. Sensor MQ-2

\subsection{Sensor MQ-2}

Sensor MQ-2 merupakan sensor yang digunakan untuk mendeteksi gas dan asap. Sensor gas dan asap ini mendeteksi konsentrasi gas yang mudah terbakar di udara serta asap. Output dari bacaan sensor MQ-2 adalah tegangan analog. Jika terdapat kebocoran gas konduktifitas sensor menjadi lebih tinggi, setiap kenaikan konsentrasi gas maka konduktifitas sensor juga naik. MQ-2 sensitif terhadap gas LPG, Propana, Hidrogen, Karbon Monoksida, Metana dan Alkohol, serta gas mudah terbakar diudara lainnya [12]. Spesifikasi dari sensor MQ-2 yaitu input tegangan $5 \mathrm{~V}$, sensitivitas pengukuran gas yang mudah terbakar dan asap mulai dari 300$10000 p p m$ [13]. Bentuk fisik sensor MQ-2 dapat dilihat pada Gambar 5.

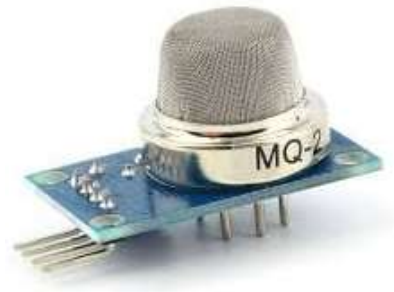

Gambar 5. Sensor MQ-2

\subsection{Sensor DHT-11}

Sensor DHT-11 merupakan sebuah sensor yang memiliki keluaran suhu dan kelembapan udara dalam bentuk data digital yang sudah dikalibrasi dengan kompleks. Sensor ini menggunakan teknik akuisisi sinyal digital eksklusif, teknologi pengindraan suhu dan kelembapan udara, kehandalan tinggi, dan stabilitas dalam jangka panjang [14]. Spesifikasi dari sensor DHT-11 yaitu tegangan input $5 \mathrm{~V}$, rentang pengukuran suhu $0-50^{\circ} \mathrm{C}$ serta kelembapan 20-90 \%RH [15]. Bentuk fisik dari sensor DHT-11 dapat dilihat pada Gambar 6.

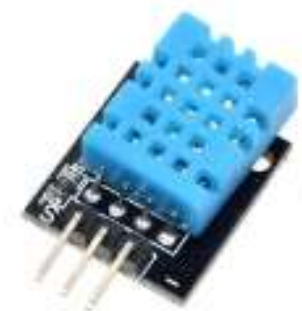

Gambar 6. Sensor DHT-11

\subsection{Push Notification}

Push notification merupakan pemberitahuan yang dapat dikirim ke pengguna melalui web dekstop dan web seluler. Pemberitahuan ini merupakan pesan gaya lansiran yang tampil pada sudut kanan atas atau bawah layar dekstop, tergantung pada sistem operasi, atau muncul di perangkat seluler dengan cara yang hampir identik dengan push notification yang dikirim dari aplikasi. Push notification dikirim ke dekstop atau layar seluler pengguna kapan pun ketika web 
browser dijalankan meskipun pengguna membuka halaman web atau tidak [16].

\subsection{API (Aplication Programming Interface) \\ Aplicarion Programming Interface} (API) adalah fungsi-fungsi pemrograman yang disediakan oleh aplikasi atau layanan agar layanan tersebut bisa diintegrasikan dengan aplikasi yang dibuat oleh pengembang lain. API adalah seperangkat aturan-aturan protokol, dan alat untuk membangun aplikasi perangkat lunak. API menentukan bagaimana komponen perangkat lunak harus berinteraksi [14].

\subsection{Perhitungan Error Pengukuran}

Pada saat pengujian alat perlu dilakukan pengukuran nilai error yang akan dihasilkan oleh alat ukuran yang dibuat dengan alat ukur yang sudah standar. Perhitungan error ini bertujuan untuk mengetahui seberapa akurat sensor dalam melakukan pengambilan data. Adapun persamaan yang digunakan untuk mencari error dinyatakan pada persamaan 1 .

$$
\operatorname{Error}(\%)=\frac{[N S-A S]}{N S} \times 100
$$

Keterangan:

NS : nilai pengukuran sensor

AS : nilai pengukuran alat standar

Ketika error yang dihasilkan dari pengukuran dirasa cukup besar, maka untuk memperkecil selisih dan error pengukuran dapat dilakukan dengan menggunakan persamaan regresi linear sederhana aga selisih dan error dapat diperkecil. Persamaan regresi linear sederhana dinyatakan pada persamaan 2.2

$$
y=a+b \cdot x
$$

Besar konstanta $a$ dan koefisien $b$ dapat ditentukan menggunakan persamaan 3 dan persamaan 4 .

$$
\begin{gathered}
a=\frac{\left(\sum y_{i}\right)\left(\sum x_{i}^{2}\right)-\left(\sum x_{i}\right)\left(\sum x_{i} y_{i}\right)}{n \sum x_{i}^{2}-\left(\sum x_{i}\right)^{2}} \\
b=\frac{n\left(\sum x_{i} y_{i}\right)-\left(\sum x_{i}\right)\left(\sum y_{i}\right)}{n \sum x_{i}^{2}-\left(\sum x_{i}\right)^{2}}
\end{gathered}
$$

Dengan keterangan :

$\mathrm{Y}=$ garis regresi

$a=$ konstanta perpotongan dengan sumbu

$b=$ koefisien regresi $\mathrm{x}=$ variabel bebas

\section{METODE PENELITIAN}

Adapun tahapan metodologi yang digunakan dalam merealisasikan penelitian tugas akhir ini dapat dilihat pada diagram alir pada Gambar 7.

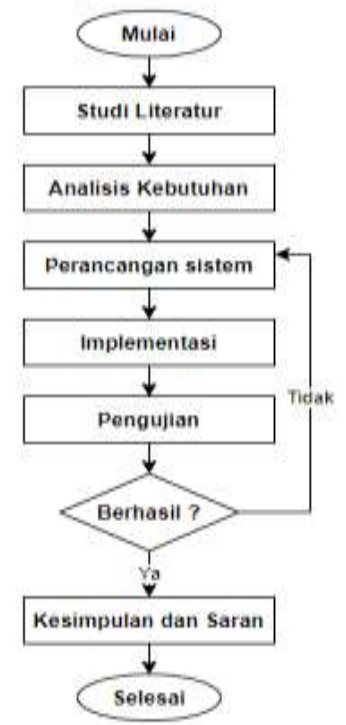

\section{Gambar 7. Diagram Alir Metodologi} Penelitian

Metodologi penelitian dimulai dengan studi literatur yang berfungsi untuk mengumpulkan informasi berupa teori-teori pendukung yang akan digunakan dalam penelitian. Setelah itu dilanjutkan metode analisis kebutuhan, yang terdiri dari analisis kebutuhan perangkat keras dan perangkat lunak. Dilanjutkan pada proses implementasi perangkat keras dan perangkat lunak. Tahap akhir yang dilakukan adalah proses pengujian sistem, mulai dari modul-modul sensor, node sensor hingga pengujian aplikasi serta pengiriman notifikasi ke pengguna.

\section{PERANCANGAN SISTEM}

Perancangan sistem yang akan dilakukan pada penelitian ini terdiri dari perancangan perangkat keras dan perangkat lunak. Perancangan perangkat keras terdiri dari perancangan node sensor. Komponenkomponen yang terdapat pada node sensor antara lain Arduino Nano, NodeMCU, sensor GP2Y1010AU0F, sensor MQ-7, sensor MQ-2, dan sensor DHT-11. Perancangan perangkat lunak terdiri dari perancangan database, perancangan perangkat lunak website, perancangan antarmuka website, dan 
perancangan API(Application programming interface). Secara umum perancangan sistem monitoring kualitas udara (PM10, asap, karbon monoksida, suhu dan kelembapan) secara realtime dengan peringatan bahaya kualitas udara tidak sehat menggunakan push notification dapat dilihat pada Gambar 8.

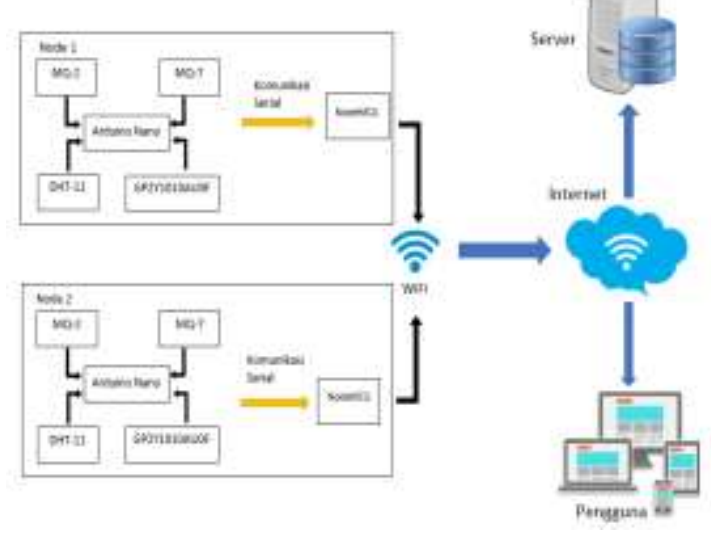

Gambar 8. Perancangan Sistem

Alur algoritma pengiriman notifikasi dapat dilihat pada Gambar 9.

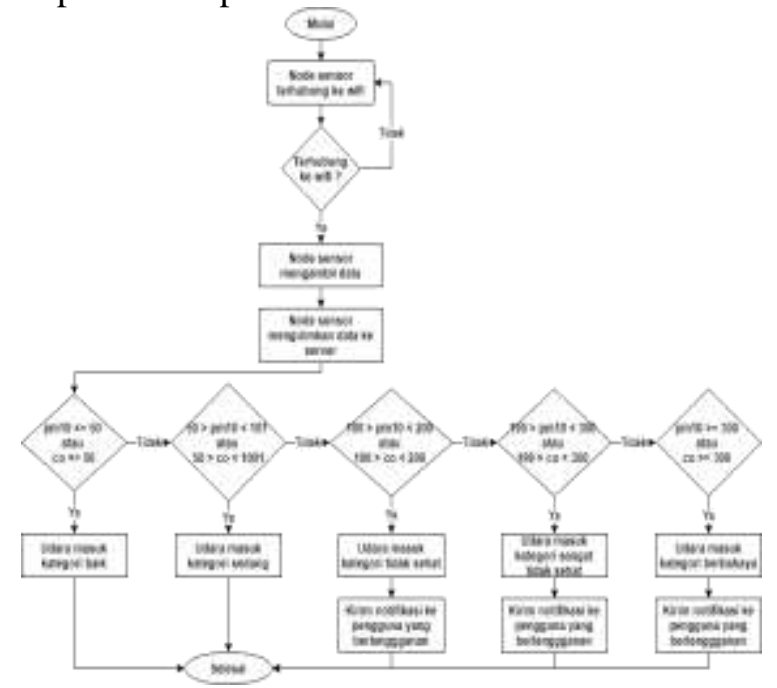

Gambar 9. Alur Algoritma Sistem

Pada Gambar 9 dijelaskan bahwa ketika nilai PM10 kurang dari sama dengan $50 \mu / \mathrm{mg}^{3}$ atau nilai co kurang dari sama dengan $50 \mathrm{ppm}$ maka kualitas udara berada pada kategori sehat dan notifikasi tidak dikirim ke pengguna. Ketika nilai PM10 lebih dari $50 \mu / \mathrm{mg}^{3}$ dan kurang dari sama dengan $100 \mu / \mathrm{mg}^{3}$ atau nilai co lebih dari $50 \mathrm{ppm}$ dan kurang dari sama dengan 100 ppm maka kualitas udara berada pada kategori sedang, dan notifikasi tidak dikirim ke pengguna. Ketika nilai PM10 lebih dari $100 \mu / \mathrm{mg}^{3}$ dan kurang dari $200 \mu / \mathrm{mg}^{3}$ atau nilai co lebih dari 100 ppm dan kurang dari 200 ppm maka kualitas udara berada pada kategori tidak sehat, dan notifikasi akan dikirim ke pengguna. Ketika nilai PM10 lebih dari sama dengan $200 \mu / \mathrm{mg}^{3}$ dan kurang dari $300 \mu / \mathrm{mg}^{3}$ atau nilai co lebih dari sama dengan $200 \mathrm{ppm}$ dan kurang dari 300 ppm maka kualitas udara berada pada kategori sangat tidak sehat, dan notifikasi akan dikirim ke pengguna. Ketika nilai PM10 lebih dari sama dengan $300 \mu / \mathrm{mg}^{3}$ atau nilai co lebih dari sama dengan 300 ppm maka kualitas udara berada pada kategori berbahaya, dan notifikasi akan dikirim ke pengguna. Pada sistem monitoring kualitas udara pengguna yang mendapatkan notifikasi merupakan pengguna yang telah mengaktifkan fitur notifikasi pada website.

\subsection{Perancangan Perangkat Keras}

\subsubsection{Perancangan Perangkat Keras}

Perancangan perangkat keras meliputi perancangan semua sensor yang digunakan. Semua sensor dihubungkan ke Arduino Nano, mulai dari sensor GP2Y1010AU0F, sensor MQ-7, sensor MQ-2 dan sensor DHT-11.

Setelah melakukan proses pemantauan, data yang diperoleh oleh sensor akan dikirimkan ke NodeMCU oleh Arduino Nano melalui komunikasi serial. NodeMCU akan meneruskan data tersebut ke server melalui wifi dan jaringan internet. Rancangan perangkat keras dapat dilihat pada Gambar 10.

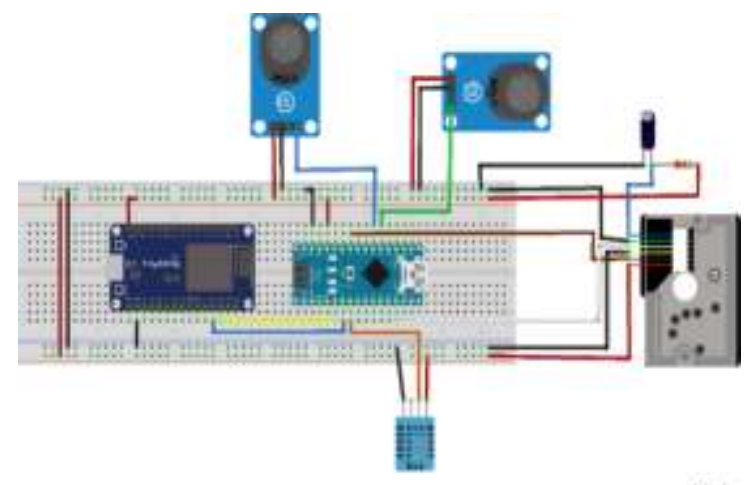

Gambar 10. Perancangan Perangkat Keras

\subsection{Perancangan Perangkat Lunak}

4.2.1. Perancangan Perangkat Lunak pada Arduino Nano

Arduino nano pada sistem digunakan untuk membaca data dari semua sensor dan melakukan transmisi data ke NodeMCU melalui komunikasi serial. Program dimulai dengan tahap inisialisasi library dan variabel. Setelah inisialisasi, dilanjutkan dengan 
pembacaan data dari sensor-sensor. Tahap selanjutnya yaitu melakukan komunikasi dengan NodeMCU melalui komunikasi serial untuk mengirimkan data hasil pembacaan ke NodeMCU. Pembacaan data dan pengiriman data sensor ke NodeMCU akan dilakukan setiap 3 detik. Diagram alir perancangan algoritma program pada Arduino Nano dapat dilihat pada Gambar 11.

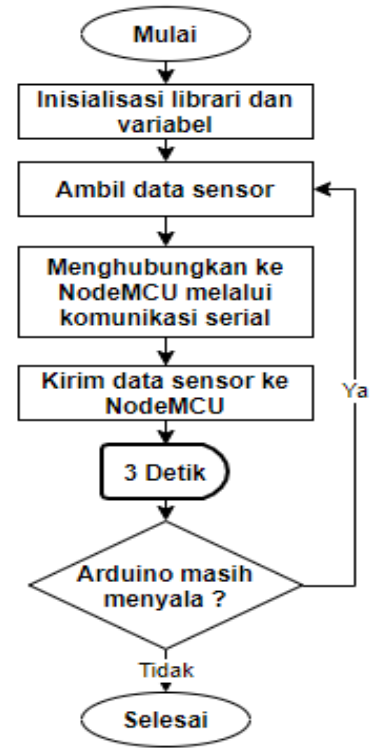

Gambar 11. Diagram Alir Algoritma Arduino Nano

4.2.2. Perancangan Perangkat Lunak pada NodeMCU

Flowchart perancangan perangkat lunak pada NodeMCU dapat dilihat pada Gambar 12.

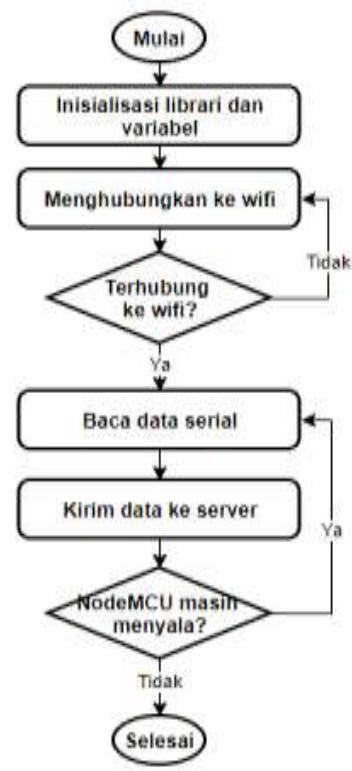

Gambar 12. Diagram Alir Algoritma NodeMCU
NodeMCU pada sistem ini berperan untuk meneruskan data serial dari Arduino ke server. Data yang telah diterima NodeMCU dari Arduino Nano akan diterukan ke server melalui jaringan internet. Flowchart algoritma kode program pada NodeMCU dimulai dengan melakukan inisialisasi library dan variabel yang digunakan. Kemudian menghubungkan ke wifi sesuai dengan SSID dan password yang telah di tentukan pada kode program NodeMCU. Ketika wifi sudah terhubung NodeMCU akan melakukan pembacaan data serial dari pengiriman Arduino, ketika data serial diterima maka data tersebut akan diteruskan ke database dengan jaringan internet melalaui wifi. Pembacaan data serial dan pengiriman data ke database akan terus dilakukan ketika NodeMCU masih dalam keadaan menyala

4.2.3. Perancangan DFD (Data Flow Diagram) DFD (Data Flow Diagram) digunakan untuk menggambarkan bagaimana suatu sistem bekerja. Sistem monitoring kualitas udara terdiri dari 2 level hak akses yaitu level administrator dan level pengguna. Rancangan DFD level 0 dari aplikasi sistem monitoring kualitas udara ditunjukkan pada Gambar 13.

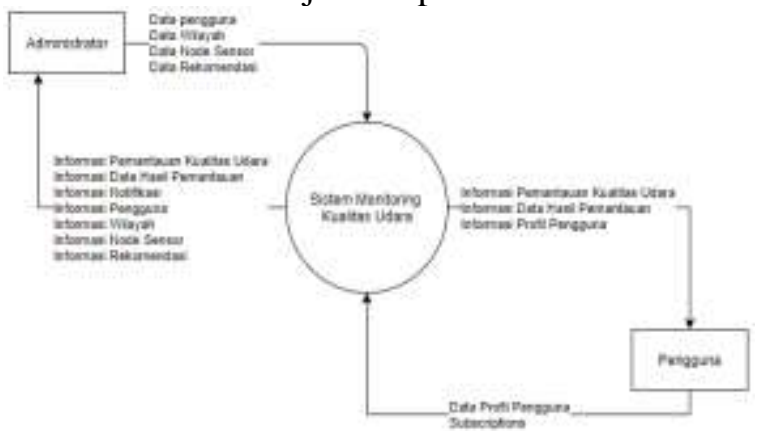

Gambar 13. DFD Level 0 Sistem Monitoring Kualitas Udara

\subsubsection{Perancangan API (Application Programming Interface) \\ Aplication Programming Interface atau} API merupakan standar komunikasi yang paling populer digunakan saat ini. API digunakan untuk proses komunikasi antara komponen perangkat keras dan perangkat lunak. Adapun API yang dibutuhkan dalam proses komunikasi tersebut adalah sebagai berikut :

1. API untuk monitoring

2. API untuk pengiriman data ke server 


\section{IMPLEMENTASI, PENGUJIAN DAN PEMBAHASAN}

\subsection{Implementasi Perangkat Keras}

Komponen-komponen keseluruhan perangkat keras merupakan gabungan dari Arduino Nano, NodeMCU dan semua modul sensor. Implementasi semua perangkat keras dapat dilihat pada Gambar 14.

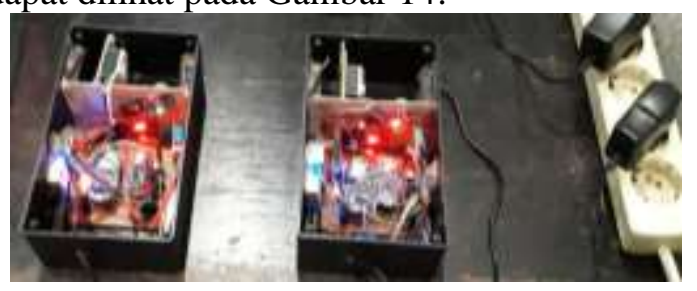

Gambar 14. Implementasi Keseluruhan

Perangkat Keras

Keseluruhan perangkat keras pada penelitian ini disebut node sensor. Node sensor merupakan perangkat yang akan melakukan proses pemantauan. Node sensor juga berperan sebagai pengirim data hasil pemantauan ke server melalui internet.

\subsection{Implementasi Perangkat Lunak}

\subsubsection{Kode Program Node Sensor}

Program utama pada node sensor, yaitu melakukan pengiriman data ke server hasil pemantauan oleh semua sensor. Kode program untuk pengiriman data dapat dilihat pada Gambar 15.

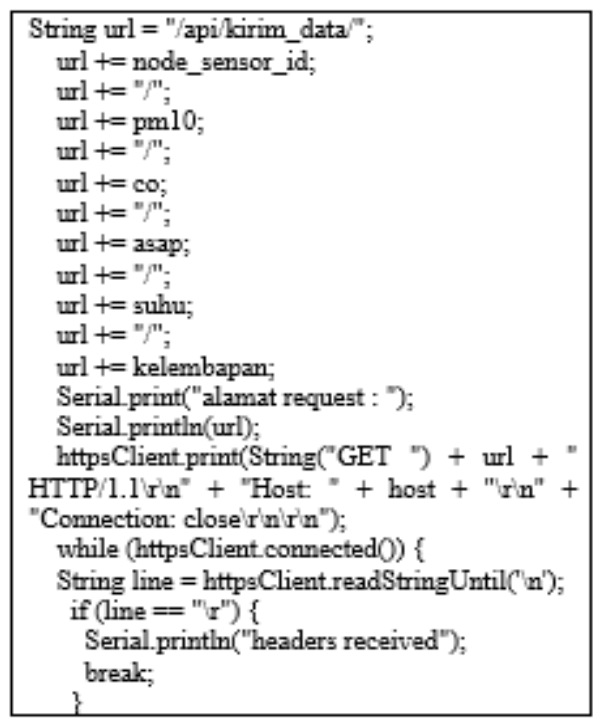

Gambar 15. Kode Program Node Sensor

\subsubsection{Database}

Pada penelitian ini, terdapat 13 tabel yang digunakan dalam proses pemantauan dan penyimpanan data hasil pemantauan dan data dari pengguna yang telah terdaftar. Database dapat dilihat pada Gambar 26.

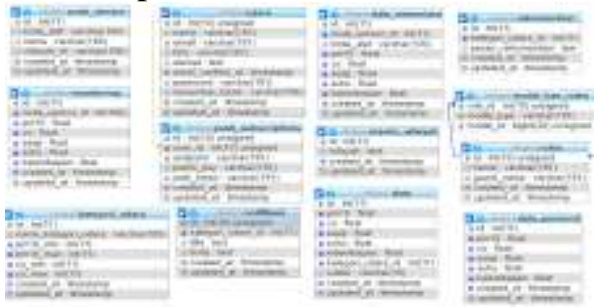

Gambar 16. Database

\subsubsection{API (Application Programming Interface)}

Pada penelitian ini, API yang digunakan untuk proses komunikasi dari perangkat lunak dan perangkat keras antara lain API untuk proses komunikasi dari perangkat keras dan perangkat lunak yaitu API pengiriman data. Tampilan API pengiriman data dapat dilihat pada Gambar 17.

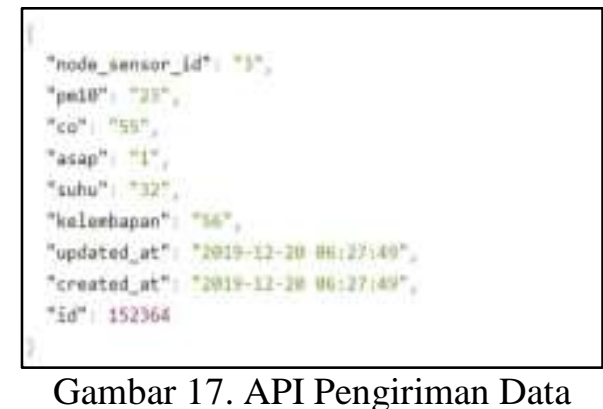

\subsection{Pengujian}

5.3.1. Pengujian Sensor GP2Y1010AU0F

Pengujian sensor GP2Y1010AU0F akan dilakukan di kantor BMKG Kelas II Mempawah yang beralamat di Jalan Raya Sei Nipah, Jungkat. Pengujian dilakukan kurang lebih selama 1 hari dengan membandingkan hasil pengukuran konsentrasi PM10 dari node sensor dan hasil pengukuran dari alat pengukuran PM10 dari BMKG. Data yang dibandingkan yaitu data rata-rata pengukuran konsentrasi PM10 per satuan jam.

Tabel 2. Pengujian Sensor GP2Y1010AU0F

\begin{tabular}{|c|c|c|c|c|c|}
\hline No. & Jam & $\begin{array}{c}\text { BMKG } \\
\left(\boldsymbol{\mu g} / \mathbf{m}^{\mathbf{3}}\right)\end{array}$ & $\begin{array}{c}\text { Sensor } \\
\left(\boldsymbol{\mu g} / \mathbf{m}^{\mathbf{3}}\right)\end{array}$ & Selisih & $\begin{array}{c}\text { Error } \\
(\boldsymbol{\%})\end{array}$ \\
\hline 1 & 6 & 3,1 & 1,10 & 0,11 & 10,32 \\
\hline 2 & 7 & 5,26 & 3,22 & 0,09 & 2,75 \\
\hline 3 & 8 & 8,59 & 6,49 & 0,26 & 4,02 \\
\hline 4 & 9 & 15,84 & 13,61 & 0,42 & 3,08 \\
\hline 5 & 10 & 19,79 & 17,49 & 0,79 & 4,51 \\
\hline
\end{tabular}




\begin{tabular}{|c|c|c|c|c|c|}
\hline 6 & 11 & 33,15 & 30,61 & 0,80 & 2,61 \\
\hline 7 & 12 & 42,74 & 40,03 & 0,97 & 2,42 \\
\hline 8 & 13 & 34,51 & 31,95 & 0,46 & 1,45 \\
\hline 9 & 14 & 26,34 & 23,92 & 0,91 & 3,79 \\
\hline 10 & 15 & 17,21 & 14,96 & 0,28 & 1,84 \\
\hline \multicolumn{6}{|c|}{ Error Rata-rata } \\
\hline
\end{tabular}

Dari hasil pengukuran Tabel 2 didapatkan nilai error yaitu 3,68\%.

\subsubsection{Pengujian Sensor MQ-7}

Pengujian sensor MQ-7 dilakukan di Laboratorium Ilmu Tanah Fakultas Pertanian. Pengujian sensor MQ-7 dilakukan dengan membandingkan Sensor MQ-7 dengan CO METER GCO-2008. Pengujian dapat dilihat pada Tabel 3.

Tabel 3. Pengujian Sensor MQ-7

\begin{tabular}{|c|c|c|c|c|}
\hline No. & $\begin{array}{c}\text { CO } \\
\text { METER } \\
(\mathbf{p p m})\end{array}$ & $\begin{array}{c}\text { MQ-7 } \\
(\mathbf{p p m})\end{array}$ & Selisih & $\begin{array}{c}\text { Error } \\
(\%)\end{array}$ \\
\hline 1 & 10,05 & 10,23 & 0,18 & 1,79 \\
\hline 2 & 10,08 & 11,01 & 0,93 & 8,45 \\
\hline 3 & 10,30 & 11,34 & 1,04 & 9,17 \\
\hline 4 & 10,40 & 11,61 & 1,21 & 10,42 \\
\hline 5 & 11,09 & 12,42 & 1,33 & 10,71 \\
\hline 6 & 11,13 & 12,11 & 0,98 & 8,09 \\
\hline 7 & 11,67 & 12,45 & 0,78 & 6,27 \\
\hline 8 & 12,12 & 12,50 & 0,38 & 3,04 \\
\hline 9 & 12,23 & 12,53 & 0,30 & 2,39 \\
\hline 10 & 12,45 & 12,76 & 0,31 & 2,43 \\
\hline \multicolumn{5}{|c|}{ Error rata-rata } \\
\hline
\end{tabular}

\subsubsection{Pengujian Sensor MQ-2}

Pengujian sensor MQ-2 dilakukan dengan memberikan asap sisa pembakaran kertas. Hal ini dilakukan untuk menguji kepekaan sensor MQ-2 dalam mendeteksi asap. Pengujian sensor MQ-2 dapat dilihat pada Gambar 18.

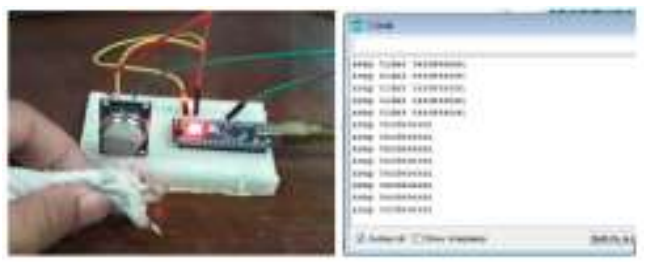

Gambar 18. Pengujian Sensor MQ-2

\subsubsection{Pengujian Sensor DHT-11}

Proses pengujian sensor DHT-11 pada penelitian ini menggunakan alat mengukur suhu dan kelembapan standar yaitu Mini Digital Thermometer \& Hygrometer. Pengujian dilakukan sebanyak 10 kali percobaan, masingmasing untuk pengujian suhu udara dan kelembapan udara. Adapun hasil dari pengujian ditunjukkan pada Tabel 5.4.

Tabel 4. Pengujian Sensor DHT-11

\begin{tabular}{|c|c|c|c|c|c|c|c|c|}
\hline \multirow{3}{*}{$\begin{array}{l}\mathbf{N} \\
\mathbf{0}\end{array}$} & \multicolumn{8}{|c|}{ Pengukuran } \\
\hline & \multicolumn{4}{|c|}{$\begin{array}{l}\text { Suhu } \\
\text { Udara }\end{array}$} & \multicolumn{4}{|c|}{$\begin{array}{l}\text { Kelembapan } \\
\text { Udara }\end{array}$} \\
\hline & NS & $\mathbf{A U}$ & $\mathbf{S}$ & $\begin{array}{c}E \\
(\%)\end{array}$ & $\begin{array}{l}\mathbf{N} \\
\mathbf{S}\end{array}$ & $\begin{array}{l}\mathbf{A} \\
\mathbf{U}\end{array}$ & $\mathbf{S}$ & $\underset{(\%)}{E}$ \\
\hline 1 & 29,0 & & & & 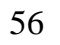 & 56 & 0 & 0,00 \\
\hline 2 & 29,0 & & & & 77 & 56 & 1 & 1,75 \\
\hline 3 & 29,0 & 29,0 & 0 & 0 & 57 & 56 & 1 & 1,75 \\
\hline 4 & 29,0 & 29,0 & 0,0 & 0,0 & 57 & 57 & 0 & 0,00 \\
\hline 5 & 29,0 & 29,6 & 0,6 & 2,07 & 57 & 57 & 0 & 0,00 \\
\hline 6 & 29,0 & 29,6 & 0,6 & 2,07 & 57 & 57 & 0 & 0,00 \\
\hline 7 & 29,0 & 29,9 & 0,9 & 3,1 & 57 & 58 & 1 & 1,75 \\
\hline 8 & 29,0 & 29,9 & 0,9 & 3,1 & 56 & 58 & 2 & 3,57 \\
\hline 9 & 29,0 & 29,9 & 0,9 & & 56 & 58 & 2 & 3,57 \\
\hline & 31,0 & 29,6 & 0,6 & 2,07 & 56 & 58 & 2 & 3,57 \\
\hline & & & & 1,55 & & & & 1,60 \\
\hline
\end{tabular}

Keterangan:

- NS : Nilai Sensor

- AU : Nilai Alat Ukur

- S : Selisih Pengukuran

- E : Error (\%)

\subsubsection{Pengujian Komunikasi Serial}

Untuk melakukan komunikasi serial, kedua perangkat harus terhubung dengan protokol UART (Universal Asynchronous Receiver Transmitter) secara internal. Protokol ini dapat digunakan sebagai antarmuka pengiriman data antara Arduino dan perangkat mikrokontrolle lainnya. Protokol komunikasi serial UART menggunakan dua buah jalur sinyal untuk berkomunikasi, yaitu jalur sinyal $\mathrm{Rx}$ (receiver) untuk menerima data dan jalur sinyal Tx (transmitter) untuk mengirimkan data. Untuk melakukan komunikasi kecepatan protokol UART harus sama. Pengujian 
Komunikasi Serial Arduino Nano dan NodeMCU dapat dilihat pada Gambar 19.

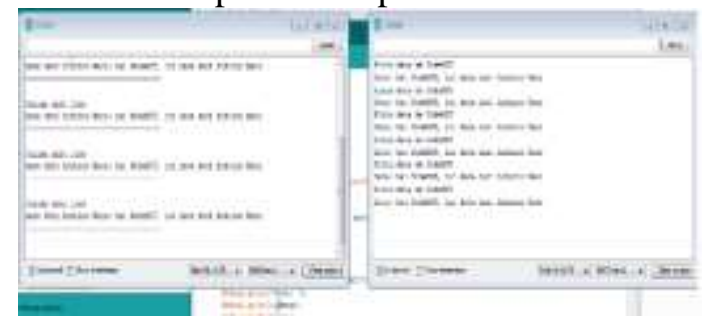

Gambar 19. Pengujian Komunikasi Serial

\subsubsection{Pengujian Pengiriman Data Dari Node} Sensor Ke Server

Pengiriman data dari node sensor ke server dilakukan secara realtime dan memerlukan koneksi internet. Parameter keberhasilan dalam melakukan pengujian ini yaitu terkirimnya data dari node sensor ke server, serta website dapat menampilkan data tersebut. Pengujian ini melibatkan perangkat keras dan perangkat lunak. Komponen perangkat keras diwakili oleh node sensor yang melakukan pengukuran, data-data yang telah diperoleh akan di teruskan ke server melalui jaringan internet. Pengujian pengiriman data dari node sensor ke server dapat dilihat pada Gambar 20.

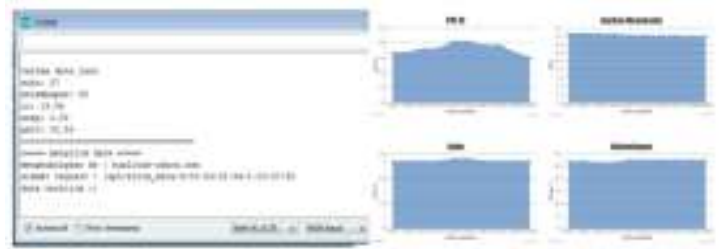

Gambar 20. Pengujian Pengirim Data

\subsubsection{Pengujian Pengiriman Push Notification}

Web push notification merupakan pemberitahuan yang akan dikirimkan server ke pengguna. Pemberitahuan ini akan secara otomatis dikirim ketika kualitas udara dalam kategori tidak sehat, sangat tidak sehat, dan berbahaya. Selain pemberitahuan tentang kualitas udara, pemberitahuan ini juga memuat informasi mengenai rekomendasi-rekomendasi yang dapat di lakukan ketika udara mulai masuk kategori tidak sehat.

Parameter keberhasilan dalam pengujian pengiriman push notification ke pengguna pada penelitian ini yaitu terkirimnya pemberitahuan atau notifikasi ke pengguna baik melalui website ataupun melalui perangkat seluler. Untuk dapat menerima pesan notifikasi, pengguna harus memberikan ijin agar browser dapat menerima pesan push notification. Pengujian pengiriman push notification dapat dilihat pada Gambar 21.

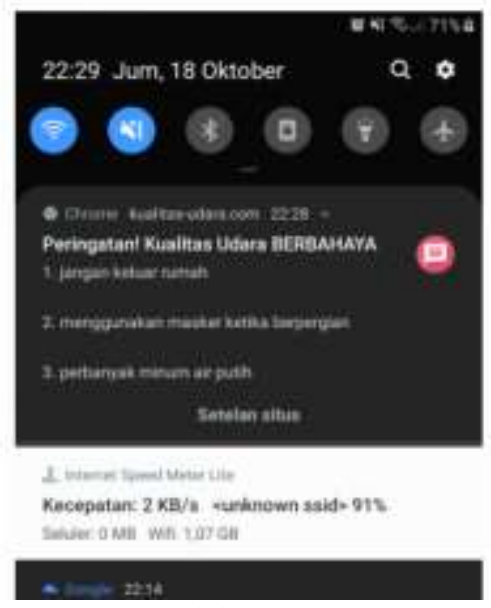

Gambar 21. Pengiriman Push Notification

\subsubsection{Pengujian Keseluruhan}

Pengujian dilakukan di Gedung UPT.

TIK UNTAN, Pengujian keseluruhan dilakukan dengan memberikan perlakuan berupa pemberian asap sisa pembakaran kertas kepada node sensor. Perlakuan dilakukan untuk menguji fungsi dari keseluruhan sistem perangkat keras dan perangkat lunak. Ketika node sensor diberikan asap sisa pembakaran kertas, kipas pada node sensor akan menghisap asap melalui ventilasi node sensor. Asap yang dihisap akan bergerak melewati sensor MQ-7, sensor MQ-2 dan sensor GP2Y1010AU0F. Hasil dari pengujian keseluruhan dapat dilihat pada Tabel 5 Hasil pengujian keseluruhan pada Tabel 5 merupakan data yang telah dirataratakan dari dua node sensor

Penentuan kategori kualitas udara mengacu pada Tabel 1 untuk pengukuran PM10 dan pengukuran CO. Ketika terdapat salah satu pengukuran baik itu dari PM10 atau CO memasuki rentang nilai $101-199 \mu \mathrm{g} / \mathrm{m}^{3}$ untuk PM10 dan 101-199 ppm untuk CO, maka kategori kualitas udara pada sistem akan menunjukkan kategori tidak sehat. Ketika pengukuran PM10 atau CO memasuki rentang nilai $200-299 \mu \mathrm{g} / \mathrm{m}^{3}$ untuk PM10 dan 200-299 ppm untuk CO, maka kategori kualitas udara pada sistem akan menjadi sangat tidak sehat. Ketika pengukuran PM10 dan CO memasuki rentang nilai lebih dari $300 \mu \mathrm{g} / \mathrm{m}^{3}$ untuk PM10 dan lebih $300 \mu \mathrm{g} / \mathrm{m}^{3}$ untuk CO maka kualitas udara pada sistem akan menunjukkan Berbahaya. 
Tabel 5. Data Pengujian Keseluruhan

\begin{tabular}{|c|c|c|c|c|c|c|c|c|}
\hline No & $\begin{array}{c}\text { Jam / } \\
\text { Tanggal }\end{array}$ & $\begin{array}{l}\text { PM10 } \\
\left(\mu \mathrm{g} / \mathrm{m}^{3}\right)\end{array}$ & $\begin{array}{c}\text { CO } \\
(\mathbf{p p m})\end{array}$ & Asap & $\begin{array}{l}\text { Suhu } \\
\left({ }^{\circ} \mathbf{C}\right)\end{array}$ & $\begin{array}{c}\text { Kelembapan } \\
(\%)\end{array}$ & $\begin{array}{c}\text { Kategori } \\
\text { Kualitas } \\
\text { Udara } \\
\end{array}$ & Notifikasi \\
\hline 1 & $\begin{array}{c}\text { Jam } 9 \text { / } \\
11-12- \\
2019\end{array}$ & 26,14 & 13,58 & $\begin{array}{c}\text { Tidak } \\
\text { Terdeteksi }\end{array}$ & 33,00 & 46,81 & Baik & $\begin{array}{c}\text { Tidak } \\
\text { Dikirim }\end{array}$ \\
\hline 2 & $\begin{array}{c}\text { Jam } 10 \text { / } \\
11-12- \\
2019\end{array}$ & 36,47 & 18,65 & $\begin{array}{c}\text { Tidak } \\
\text { Terdeteksi }\end{array}$ & 33,11 & 45,39 & Baik & $\begin{array}{c}\text { Tidak } \\
\text { Dikirim }\end{array}$ \\
\hline 3 & $\begin{array}{c}\text { Jam } 11 \text { / } \\
11-12- \\
2019\end{array}$ & 156,73 & 23,61 & Terdeteksi & 33,54 & 43,84 & $\begin{array}{l}\text { Tidak } \\
\text { Sehat }\end{array}$ & Terkirim \\
\hline 4 & $\begin{array}{c}\text { Jam } 12 \text { / } \\
11-12- \\
2019\end{array}$ & 351,46 & 38,36 & Terdeteksi & 34,00 & 42,89 & Berbahaya & Terkirim \\
\hline 5 & $\begin{array}{c}\text { Jam } 13 \text { / } \\
11-12- \\
2019\end{array}$ & 261,41 & 28,37 & Terdeteksi & 33,72 & 39,40 & $\begin{array}{l}\text { Sangat } \\
\text { Tidak } \\
\text { Sehat }\end{array}$ & Terkirim \\
\hline 6 & $\begin{array}{c}\text { Jam } 14 \text { / } \\
11-12- \\
2019\end{array}$ & 182,69 & 25,04 & Terdeteksi & 32,51 & 34,15 & $\begin{array}{l}\text { Tidak } \\
\text { Sehat }\end{array}$ & Terkirim \\
\hline 7 & $\begin{array}{c}\text { Jam } 15 \text { / } \\
11-12- \\
2019\end{array}$ & 130,68 & 21,28 & Terdeteksi & 33,16 & 36,80 & $\begin{array}{l}\text { Tidak } \\
\text { Sehat }\end{array}$ & Terkirim \\
\hline 8 & $\begin{array}{c}\text { Jam } 16 \text { / } \\
11-12- \\
2019\end{array}$ & 60,18 & 18,60 & $\begin{array}{c}\text { Tidak } \\
\text { Terdeteksi }\end{array}$ & 32,94 & 34,62 & Sedang & $\begin{array}{c}\text { Tidak } \\
\text { Dikirim }\end{array}$ \\
\hline 9 & $\begin{array}{c}\text { Jam } 17 \text { / } \\
11-12- \\
2019\end{array}$ & 20,86 & 11,57 & $\begin{array}{c}\text { Tidak } \\
\text { Terdeteksi }\end{array}$ & 32,62 & 32,57 & Baik & $\begin{array}{c}\text { Tidak } \\
\text { Dikirim }\end{array}$ \\
\hline 10 & $\begin{array}{c}\text { Jam } 18 \text { / } \\
11-12- \\
2019\end{array}$ & 9,28 & 8,77 & $\begin{array}{c}\text { Tidak } \\
\text { Terdeteksi }\end{array}$ & 29,87 & 41,63 & Baik & $\begin{array}{c}\text { Tidak } \\
\text { Dikirim }\end{array}$ \\
\hline
\end{tabular}

\section{PENUTUP}

\subsection{Kesimpulan}

Berdasarkan pada tahapan penelitian yang telah dilakukan, maka dapat disimpulkan:

1. Sistem yang telah dibuat dapat memantau kualitas udara berupa pemantauan konsentrasi PM10, pengukuran gas karbon monoksida, deteksi asap, pengukuran suhu dan kelembapan secara realtime yang telah ditampilkan ke antarmuka website. Pemantauan dapat dilakukan seharian penuh, data yang ditampilkan berupa data realtime pengukuran dan data yang telah dirata-ratakan dalam satuan jam.

2. Sistem yang telah dibuat dapat mengirimkan push notification kepada pengguna yang telah mengaktifkan fitur notifikasi. Pengiriman notifikasi dilakukan ketika rata-rata kualitas kategori udara per jam berada pada kategori tidak sehat pada rentang pengukuran $101 \mu \mathrm{g} / \mathrm{m}^{3}$ sampai 199 $\mu \mathrm{g} / \mathrm{m}^{3}$, sangat tidak sehat pada rentang 
pengukuran $200 \mu \mathrm{g} / \mathrm{m}^{3}$ sampai 299 $\mu \mathrm{g} / \mathrm{m}^{3}$, dan berbahaya pada rentang pengukuran lebih dari $300 \mu \mathrm{g} / \mathrm{m}^{3}$.

\subsection{Saran}

Saran untuk pengembangan penelitian selanjutnya adalah:

1. Pengembangan ke arah aplikasi android lebih di harapkan sehingga memudahkan pengguna dalam mengakses aplikasi untuk melakukan pemantauan.

2. Disarankan untuk penelitian selanjutnya agar dapat menambah node sensor sehingga data pemantauan lebih akurat.

3. Disarankan untuk penelitian selanjutnya menggunakan sensor yang memiliki nilai baca yang lebih akurat, dengan nilai error yang relatif kecil.

\section{DAFTAR PUSTAKA}

[1] R. N. Wijayanti, Analisis Pengaruh Kepadatan Lalu Lintas Terhadap Konsentrasi PM10, Semarang: Universitas Diponegoro, 2010.

[2] USEPA, "Health Effects of Particulate Matter," 12 2013. [Online]. Available: https://www3.epa.gov/pm/health.html. [Diakses 1512 2019].

[3] W. A. Wardana, Dampak pencemaran lingkungan, Yogyakarta: Andi, 2001.

[4] Y. D. Pramitasari, "Hubungan Antara Paparan Asap Dengan Erosi Gigi," Fakultas Kesehatan Masyarakat Universitas Diponegoro, Bandung, 2014.

[5] F. Kreith, Prinsip-Prinsip Perpindahan Panas Edisi Ketiga, Jakarta: Erlangga, 1991.

[6] Arduino, "What is Arduino?," 17 oktober 2018. [Online]. Available: https://www.arduino.cc/en/Guide/Introd uction.

[7] Y. H. Putra, "Sistem Pemantauan Dan Pengendalian Nutrisi, Suhu, Dan Tinggi Air Pada Pertanian Hidroponik Berbasis Website," Jurnal Coding, Sistem Komputer Untan, pp. 128-138, 2018.

[8] Datasheet, "NodeMCU ESP8266," 2017.

[9] Datasheet, "GP2Y1010AU0F," 2018.
[10] L. Agustinus, "Rancang Bangun Prototype Pendeteksi Kadar CO sebagai Informasi Kealitas Udara Berbasis Mikrokontroler," Jurnal Coding Sistem Komputer Untan, pp. 44-53, 2015.

[11] Datasheet, "MQ-7," henan, 2018.

[12] I. N. B. P. d. W. Broto, "Pembuatan Alat Pendeteksi Api dan Asap Berbasis Mikrokontroller Arduino Uno dan Sensor MQ-2 Keluaran Sms Gateway," Prosiding Seminar Nasional Fisika (EJournal), 2017.

[13] Datasheet, "MQ-2," henan, 2018.

[14] M. Sabiran, "Implementasi Wireless Sensor Network Pada Sistem Pemantauan dan Pengontrolan Budidaya Tanaman Pada Rumah Kaca (Green House) Berbasis Website," Jurnal Coding Sistem Komputer UNTAN, 2018.

[15] Datasheet, "DHT-11," 2018.

[16] Airship, "Web Push Notifications Explained," $10 \quad 10$ 2018. [Online]. Available: https://www.airship.com/resources/expl ainer/web-push-notifications-explained/.

[17] R. A. K. dony Ariyus, Komunikasi Data, Yogyakarta: Andi, 2008.

[18] JSON, “Pengenalan JSON,” 13102018. [Online]. Available: http://www.json.org/json-id.html. 